Arq. Bras. Med. Vet. Zootec., v.67, n.5, p.1272-1278, 2015

\title{
Avaliação hemogasométrica, bioquímica e hematológica de ovinos suplementados com melão
}

[Effects of sudden intake of melon on blood gas, biochemical and hematological parameters of sheep]

\author{
F.L.C. Oliveira ${ }^{1}$, R.A. Barrêto-Júnior ${ }^{2}$, A.H.H. Minervino ${ }^{3}$, L.F. Reis ${ }^{1}$, C.A.S.C. Araújo ${ }^{1}$, \\ F.A.M.L. Rodrigues ${ }^{1}$, R.S. Sousa ${ }^{1}$, J.S. Gameleira ${ }^{2}$, F.J.A. Souza ${ }^{2}$, \\ C.S. Mori ${ }^{1}$, E.L. Ortolani ${ }^{1 *}$ \\ ${ }^{1}$ Faculdade de Medicina Veterinária e Zootecnia - Universidade de São Paulo - São Paulo, SP \\ ${ }^{2}$ Universidade Federal Rural do Semiárido - Mossoró, RN \\ ${ }^{3}$ Instituto de Biodiversidade e Floresta - Universidade Federal do Oeste do Pará - Santarém, PA
}

\begin{abstract}
RESUMO
O presente trabalho avaliou os efeitos da administração de duas diferentes quantidades de melão sobre variáveis hemogasométricas, bioquímicas e hematológicas de ovinos não adaptados. Foram utilizados 12 ovinos canulados, pesando 25kg de peso vivo, que nunca receberam ração concentrada. Os animais receberam dieta à base de feno (2,3\% do peso vivo) e água à vontade. Os ovinos foram distribuídos aleatoriamente em dois grupos e receberam $25 \%$ ou $75 \%$ da matéria seca (MS) da dieta de melão triturado (G25\% e G75\%, respectivamente) diretamente no rúmen. Foram realizadas coletas de sangue e determinação do pH ruminal nos seguintes tempos: zero, 3, 6, 12, 18 e 24 horas após oferecimento do melão. Foi realizada análise hemogasométrica, do volume globular, determinação da concentração plasmática de lactato-L, glicose e osmolaridade sérica. No G25\%, o pH sanguíneo variou entre 7,40 e 7,31, enquanto o G75\% apresentou $\mathrm{pH}$ entre 7,38 e 7,26. Maiores concentrações de glicose plasmática foram detectadas no G75\% no T3, T6 e T12 (P<0,05). Os ovinos que receberam 25\% de melão mantiveram parâmetros sanguíneos dentro da normalidade, ao passo que, no G75\%, os ovinos apresentaram discreta acidose metabólica sistêmica e hiperglicemia. A suplementação com 25\% de melão pode ser uma alternativa segura na alimentação de ovinos.
\end{abstract}

Palavras-chave: acidose, pH, melão, ovinos, sangue

\begin{abstract}
This study evaluated the effects of two different amounts of melon on blood gas, biochemical and hematological variables of sheep not adapted. We used 12 cannulated sheep weighing $25 \mathrm{~kg}$ which never received concentrate. The animals received hay-based diet (2.3\% of body weight) and water ad libitum. The sheep were randomly divided into two groups and received $25 \%$ or $75 \%$ of the dry matter (DM) of the diet of crushed melon (G25\% and G75\%, respectively) directly into the rumen. Blood collection and determination of ruminal $\mathrm{pH}$ were made at the following times: zero, three, six, 12, 18 and 24 hours after administration of the fruit. In whole blood was performed blood gas analysis and packed cell volume; in the plasma it was determined the concentrations of L-Lactate and glucose and in the serum the osmolarity. At G25\% the blood pH ranged between 7.40 and 7.31, while G75\% showed pH between 7.38 and 7.26. Higher concentrations of plasma glucose were detected in G75\% after 3, 6 and 12 hours ( $P$ $<0.05)$. Sheep receiving $25 \%$ of melon showed blood parameters within the normal range, while in the G75\%, sheep had a mild systemic metabolic acidosis and hyperglycemia.
\end{abstract}

Keywords: acidosis, $\mathrm{pH}$, melon, sheep, blood

Recebido em 29 de outubro de 2014

Aceito em 3 de março de 2015

*Autor para correspondência (corresponding author)

E-mail: ortolani@usp.br 


\section{INTRODUÇÃo}

Com a intensificação do sistema de criação de ovinos e o consequente aumento de custos decorrentes da alimentação dos animais, é necessário adotar alternativas, como a utilização de resíduos ou subprodutos diversos disponíveis localmente (Lima et al., 2012). Uma das opções passíveis de serem utilizadas como suplementação alimentar refere-se aos resíduos de frutas, produzidos em grandes quantidades em todas as regiões do Brasil, que são carboidratos de alta qualidade. Dentre os diferentes resíduos, ganha destaque o uso do melão, uma vez que sua produção é contínua e em larga escala, com abundância desse subproduto em especial na região Nordeste do país, onde se concentra mais da metade do rebanho ovino brasileiro, e onde o sistema produtivo tem grande demanda de tecnificação e intensificação (Lousada Júnior et al., 2005).

Devido à alta disponibilidade do melão e a eventuais excessos de produção, essa fruta tem sido empregada como fonte alternativa na alimentação de ovinos. Já foi comprovada a viabilidade da substituição de parte de grãos ricos em energia na dieta pelo melão (Lima et al., 2012). Contudo, o aporte de carboidratos solúveis a ruminantes não adaptados pode provocar quadros de acidose ruminal e posteriormente de acidose sistêmica, levando à queda do pH sanguíneo, desidratação e até morte (Vieira et al., 2006; Barrêto Júnior et al., 2008; Ortolani et al., 2010).

A acidose láctica ruminal aguda (ALRA) é uma enfermidade típica de manejo alimentar incorreto ou inadequado. Entre as práticas mais observadas, destaca-se a introdução, em curto espaço de tempo, de dietas ricas em carboidratos, sem adequada adaptação, para ruminantes criados extensivamente. Essa enfermidade também pode ocorrer quando os animais têm livre acesso a depósitos de ração concentrada, baixo oferecimento temporário de fibra dietética, ou quando ocorrem erros no oferecimento de ração proveniente de máquinas distribuidoras mal reguladas. Animais que recebem dietas hiperglucídicas quando estão sendo preparados para exposições também estão predispostos a terem ALRA (Dunlop, 1972; Howard, 1981; Radostits et al., 2007).
Existem dois tipos de acidose ruminal. A primeira é de grau mais leve, causada por excesso de ácidos de cadeia curta (ACC), em especial pelo ácido propiônico, também denominada de acidose ruminal subaguda, cujo $\mathrm{pH}$ ruminal diminui abaixo dos valores considerados normais $(5,9-7,2)$, permanecendo o pH entre 5,6 a 5,1 quando nem sempre são constatados sintomas clínicos evidentes (Owens et al., 1998; Krause et al., 2006; Nagaraja e Titgemeyer, 2007; Reis et al., 2014).

Além desse tipo supracitado, existe outra categoria mais grave da enfermidade, conhecida como acidose láctica ruminal aguda, em que, além do excesso de ACCs, produzido nos primórdios do quadro, também é gerada grande quantidade de ácido láctico, o qual provoca intensa redução no pH (abaixo de 5,1), devido ao grande potencial de acidez desse composto. Tal acúmulo de ácidos gera um expressivo quadro de anorexia, síndrome desidratação, diarreia, depressão no estado geral, taquicardia, aumento de volume no flanco ventral esquerdo, acidose metabólica, entre outras manifestações (Dunlop, 1972; Ortolani et al., 1980; Owens et al., 1998; Radostits et al., 2007; Enemark, 2008). Ainda são desconhecidas as consequências da ingestão súbita de melão sobre parâmetros sanguíneos de ovinos. Desse modo, objetivou-se avaliar as variáveis hemogasométrica, hematológica e bioquímica de ovinos suplementados com duas diferentes quantidades de melão.

\section{MATERIAL E MÉTODOS}

O presente trabalho foi aprovado pela comissão de ética no uso de animais da Faculdade de Medicina Veterinária e Zootecnia, protocolado com o n ${ }^{\circ} .2141 / 2011$.

Foram utilizados 12 ovinos machos mestiços da raça Santa Inês, providos de cânula ruminal, com cerca de $25 \pm 3 \mathrm{~kg}$ de peso vivo e $8 \pm 2$ meses de idade. Os animais foram mantidos em baias coletivas, com livre acesso a água e sal mineral (Ovinofós ${ }^{\circledR}$, Tortuga Companhia Zootécnica), e alimentados com dieta basal composta de volumoso (feno de capim Cynodon Dactylon (L) Pers - Coast cross) oferecida na base de 2,3\% do peso vivo. Os ovinos nunca haviam sido alimentados previamente com ração concentrada, nem mesmo polpa de melão ou de outras frutas e raízes. 
Os animais passaram por período de adaptação às instalações e ao manejo alimentar por um período de 30 dias. O lote foi vermifugado com endectocida à base de Moxidectina (Cydectin ${ }^{\circledR}$, Zoetis Saúde Animal, São Paulo, Brasil).

Os ovinos foram aleatoriamente divididos em dois grupos iguais de seis animais cada: (G25\%) oferta súbita de $25 \%$ da MS da dieta de melão; (G75\%) oferta súbita de 75\% MS da dieta de melão. Para escolha dos frutos, foi determinado o grau Brix, por meio de refratômetro digital Atago modelo PR-101, com escala de 0 a $45^{\circ} \mathrm{Bx}$ (AOAC, 1992) e análise bromatológica segundo técnicas clássicas (Silva e Queiróz, 2002). Para os dois grupos, foram utilizados melões que tinham em média $12,5^{\circ} \mathrm{Bx} \pm 0,3$ com a seguinte composição bromatológica: 7,3 $\pm 0,2 \%$ de matéria seca; $9,30 \pm 0,1 \%$ de matéria mineral; $90,70 \pm 0,3 \%$ de matéria orgânica; 11,58 $\pm 0,33 \%$ de proteína bruta; $7,62 \pm 0,25 \%$ de extrato etéreo; $20,58 \pm 0,2 \%$ de fibra em detergente neutro; $16,68 \pm, 01 \%$ de fibra em detergente ácido; $69,94 \pm 0,21 \%$ de carboidratos totais; $49,36 \pm 0,15 \%$ de carboidratos-não-fibrosos e $5,86 \pm 0,02 \%$ de lignina.

A administração intrarruminal do melão foi feita por meio da cânula, triturando em um liquidificador convencional a fruta integral, com exceção das sementes, obtendo-se um conteúdo pastoso. Para o cálculo da quantidade administrada desse conteúdo, considerou-se a ingestão de matéria seca média de $2,3 \%$ do peso vivo dos animais e a matéria seca da fruta. Assim, hipoteticamente, ovinos de $25 \mathrm{~kg}$ receberam 1.970 e $5.900 \mathrm{~g}$ de matéria fresca da fruta, nos grupos G25\% e G75\%, respectivamente. As quantidades de melão foram calculadas individualmente.

Foi realizada coleta de sangue nos seguintes tempos: Basal (T0) imediatamente antes da administração do melão e após início da administração do suplemento, decorridas 3 horas (T3); 6 horas (T6); 12 horas (T12); 18 horas (T18) e 24 horas (T24). As amostras de sangue total, para análise hemogasométrica $(\mathrm{pH}$, bicarbonato e excesso de ácidos e bases), foram obtidas por meio de punctura da veia jugular externa, com seringa plástica descartável heparinizada de $3 \mathrm{~mL}$, conforme descrito por Sucupira e Ortolani (2003) e seguindo os cuidados de conservação da amostra preconizados por Lisboa et al. (2001). O tempo máximo decorrido entre a coleta de sangue e a análise hemogasométrica foi de uma hora.

Utilizaram-se ainda tubos de coleta a vácuo (Becton, Dickinson and Company, modelo vacutainer $^{\circledR}$, São Paulo-SP, Brasil) sem anticoagulante e contendo fluoreto de sódio acrescido de ácido dietilenodiamino tetra-acético (EDTA) e tubos com EDTA. Os tubos sem anticoagulante foram mantidos em temperatura ambiente por 40 minutos até a completa formação do coágulo e então centrifugados por 15 minutos a 1.000 x $g$ para obtenção do soro. Os tubos com fluoreto foram conservados em geladeira $\left(2\right.$ a $\left.6{ }^{\circ} \mathrm{C}\right)$ por até 4 horas e submetidos à centrifugação por 10 minutos a 1.000 x $g$ para obtenção do plasma. As amostras coletadas em tubos com EDTA foram acondicionadas em geladeira (2 a $6{ }^{\circ} \mathrm{C}$ ) por até 4 horas e então utilizadas para determinação do volume globular.

As amostras de soro e plasma foram acondicionadas em duas alíquotas, em microtubos plásticos eppendorf ${ }^{\circledR}$, e congeladas a $20^{\circ} \mathrm{C}$ negativos, sendo descongeladas uma única vez para cada análise realizada. As amostras de soro foram utilizadas para determinação da osmolaridade sérica, ao passo que as amostras de plasma foram utilizadas para determinação da concentração de ácido láctico levógiro (L) e glicose.

Para determinação do volume globular, utilizouse a técnica do micro-hematócrito (Jain, 1986). As mensurações do $\mathrm{pH}$, bicarbonato (HCO3-) e excesso de ácidos e bases (ABE) foram realizadas por meio do aparelho de hemogasometria portátil (iStat ${ }^{\circledR}$, Abbot Diagnósticos, São Paulo, Brasil), utilizando cartuchos comerciais da mesma marca.

A determinação do ácido láctico-L e da glicose plasmáticos foi realizada em analisador bioquímico automático da marca Randox, modelo RX Daytona (Antrium, UK), utilizandose kits comerciais da mesma marca. O ácido láctico-L foi realizada pelo método de UV enzimático, utilizando Lactato Desidrogenase, e a análise de glicose foi realizada pelo método enzimático colorimétrico. A determinação da osmolaridade sérica foi obtida em osmômetro por ponto de congelamento (Advanced $^{\mathrm{TM}}$ 
Instruments, modelo The Advanced MicroOsmometer 3300, São Paulo, Brasil).

Inicialmente todos os dados foram testados quanto à sua distribuição por meio do teste de Kolmogorov-Smirnov. Caso alguma variável apresentasse distribuição não gaussiana, os dados seriam transformados em função logarítmica. Os dados foram então analisados por meio de análise de variância de duas vias de medidas repetidas no tempo (Repeated mesures Two-way ANOVA), seguida de teste de comparação de médias de Bonferroni, avaliando-se a diferença entre os grupos experimentais e entre os diferentes tempos de coleta. As análises foram realizadas com auxílio de software estatístico
(GraphPad Prisma® ${ }^{\circledR}$, GraphPad Software Inc., La Jola-Ca, USA).

\section{RESULTADOS E DISCUSSÃO}

Na Tabela 1, estão apresentados os resultados médios e desvios padrão do $\mathrm{pH}$, bicarbonato sanguíneo e pH ruminal no decorrer do experimento. Dentro do grupo G25\% observaram-se maiores valores de $\mathrm{pH}$ sanguíneo no T0, comparando-se com o T18 e T24 $(\mathrm{P}<0,05)$. No grupo $75 \%$ ocorreu diminuição do $\mathrm{pH}$ sanguíneo a partir do $\mathrm{T} 12(\mathrm{P}<0,05)$. Não houve diferença dessa variável entre os dois grupos estudados, em cada um dos tempos avaliados $(\mathrm{P}>0,05)$.

Tabela 1. Valores médios e desvios padrão do pH e bicarbonato sanguíneo dos ovinos alimentados com $25 \%$ e $75 \%$ de melão subitamente no decorrer do experimento

\begin{tabular}{ccccccc} 
Tempos & \multicolumn{2}{c}{$\mathrm{pH}$ ruminal } & \multicolumn{2}{c}{$\mathrm{pH}$ sanguíneo } & \multicolumn{2}{c}{ Bicarbonato (mMol/L) } \\
\hline & $\begin{array}{c}\mathrm{G} 25 \% \\
(\mathrm{M} \pm \mathrm{DP})\end{array}$ & $\begin{array}{c}\mathrm{G} 75 \% \\
(\mathrm{M} \pm \mathrm{DP})\end{array}$ & $\begin{array}{c}\mathrm{G} 25 \% \\
(\mathrm{M} \pm \mathrm{DP})\end{array}$ & $\begin{array}{c}\mathrm{G} 75 \% \\
(\mathrm{M} \pm \mathrm{DP})\end{array}$ & $\begin{array}{c}\text { G25\% } \\
(\mathrm{M} \pm \mathrm{DP})\end{array}$ & $\begin{array}{c}\text { G75\% } \\
(\mathrm{M} \pm \mathrm{DP})\end{array}$ \\
\hline 0 & $6,580 \pm 0,13 \mathrm{a}$ & $6,327 \pm 0,33 \mathrm{a}$ & $7,381 \pm 0,04 \mathrm{a}$ & $7,382 \pm 0,04 \mathrm{a}$ & $27,5 \pm 5,95 \mathrm{a}$ & $25,5 \pm 1,22 \mathrm{a}$ \\
3 & $5,523 \pm 0,13 \mathrm{~b}$ & $5,810 \pm 0,10 \mathrm{~b}$ & $7,402 \pm 0,06 \mathrm{a}$ & $7,355 \pm 0,01 \mathrm{a}$ & $27,5 \pm 5,66 \mathrm{a}$ & $27,4 \pm 2,74 \mathrm{a}$ \\
6 & $5,585 \pm 0,27 \mathrm{~b}$ & $4,985 \pm 0,22 \mathrm{~b}$ & $7,380 \pm 0,05 \mathrm{a}$ & $7,345 \pm 0,03 \mathrm{a}$ & $24,5 \pm 4,66 \mathrm{a}$ & $23,8 \pm 3,55 \mathrm{a}$ \\
12 & $5,857 \pm 0,15 \mathrm{~b}$ & $4,455 \pm 0,23 \mathrm{~b}$ & $7,320 \pm 0,08 \mathrm{a}$ & $7,259 \pm 0,05 \mathrm{~b}$ & $22,8 \pm 3,79 \mathrm{~b}$ & $18,2 \pm 3,02 \mathrm{~b}$ \\
18 & $6,328 \pm 0,24 \mathrm{a}$ & $4,347 \pm 0,12 \mathrm{~b}$ & $7,314 \pm 0,07 \mathrm{~b}$ & $7,263 \pm 0,08 \mathrm{~b}$ & $22,6 \pm 3,26 \mathrm{~b}$ & $17,7 \pm 3,57 \mathrm{~b}$ \\
24 & $6,398 \pm 0,19 \mathrm{a}$ & $4,407 \pm 0,19 \mathrm{~b}$ & $7,317 \pm 0,05 \mathrm{~b}$ & $7,282 \pm 0,06 \mathrm{~b}$ & $24,3 \pm 4,23 \mathrm{Ab}$ & $17,6 \pm 4,60 \mathrm{Bb}$ \\
\hline
\end{tabular}

Letras maiúsculas distintas nas linhas significam diferença estatística entre os grupos. Letras minúsculas distintas nas colunas significam diferença entre o T0 e demais Tempos de coleta.

O pH sanguíneo no G25\% teve pequena queda, estabilizando-se ao final do experimento no $\mathrm{pH}$ 7,31, embora um animal desse grupo apresentou isoladamente $\mathrm{pH}$ 7,20. Segundo Ortolani (2003), ovinos hígidos podem apresentar valores de referência dessa variável de 7,28 a 7,42, estando assim todos os animais, com exceção de um, dentro da faixa de normalidade, o que ratifica o que foi descrito por Nagaraja e Lechtenberg (2007). Já no grupo G75\%, embora o pH sanguíneo atingisse, nos seus menores valores médios, 7,26, o que seria considerado acidose sistêmica moderada, em três animais o pH caiu pontualmente, em Tempos diferentes, para 7,10, 7,18 e 7,20, denotando acidose mais severa, semelhante ao descrito pelos principais autores para a ALRA (Dunlop, 1972; Owens et al., 1998; Radostits et al., 2007).
Foi verificada queda da concentração de bicarbonato sanguíneo a partir do T12, em ambos os grupos, mantendo-se até o final do experimento $(\mathrm{P}<0,05)$. Houve diferença entre os dois grupos quanto à concentração de bicarbonato sanguíneo no T24 $(\mathrm{P}<0,05)$, tendo o G25\% maior concentração desse composto do que o grupo G75\%.

Os animais do G25\% não manifestaram alterações sanguíneas evidentes após o súbito oferecimento de melão, que deve ter provocado acidose ruminal por ACC (subaguda) durante a $3^{\mathrm{a}}$ a $6^{\mathrm{a}}$ hora, como pode ser observado pelo valor do $\mathrm{pH}$ ruminal na Tabela 1 . No G75\%, todos os ovinos apresentaram alterações sanguíneas indicativas de acidose láctica ruminal aguda, com pH ruminal inferior a 5,0 a partir do T6 até o final do estudo (Reis et al., 2014). 
Na Tabela 2, estão apresentados os resultados médios e desvios padrão da concentração de excesso de ácido-base (ABE) e do lactato $\mathrm{L}$ $(\mathrm{mMol} / \mathrm{L})$ sanguíneo no decorrer do experimento. Os valores de ABE mantiveram-se dentro dos valores de normalidade para espécie durante do todo o experimento no G25\%.
Menores valores de ABE foram detectados no G25 no T12 e T18 e no G75\% a partir do T12 $(\mathrm{P}<0,01)$ em relação ao T0. Observou-se diferença entre grupos quanto ao $\mathrm{ABE}$ sanguíneo no T24 $(\mathrm{P}<0,05)$, destacando-se o deficit de bases maior no $\mathrm{G} 75 \%$.

Tabela 2. Valores médios e desvios padrão do ABE e do lactato L (mMol/L) sanguíneo dos ovinos alimentados subitamente com $25 \%$ e $75 \%$ de melão no decorrer do experimento

\begin{tabular}{ccccc}
\hline Tempos & \multicolumn{2}{c}{ ABE } & \multicolumn{2}{c}{ Lactato L (mMol/L) } \\
\hline & $\begin{array}{c}\mathrm{G} 25 \% \\
(\mathrm{M} \pm \mathrm{DP})\end{array}$ & $\begin{array}{c}\mathrm{G} 75 \% \\
(\mathrm{M} \pm \mathrm{DP})\end{array}$ & $\begin{array}{c}\mathrm{G} 25 \% \\
(\mathrm{M} \pm \mathrm{DP})\end{array}$ & $\begin{array}{c}\mathrm{G} 75 \% \\
(\mathrm{M} \pm \mathrm{DP})\end{array}$ \\
\hline 0 & $3,0 \pm 6,81 \mathrm{a}$ & $0,0 \pm 0,89 \mathrm{a}$ & $1,13 \pm 0,27 \mathrm{a}$ & $1,34 \pm 0,40 \mathrm{a}$ \\
3 & $3,3 \pm 6,53 \mathrm{a}$ & $2,7 \pm 4,27 \mathrm{a}$ & $1,98 \pm 1,07 \mathrm{a}$ & $1,68 \pm 0,41 \mathrm{a}$ \\
6 & $-0,2 \pm 5,42 \mathrm{a}$ & $-0,2 \pm 4,49 \mathrm{a}$ & $2,64 \pm 1,10 \mathrm{~b}$ & $2,73 \pm 0,51 \mathrm{~b}$ \\
12 & $-3,0 \pm 5,29 \mathrm{~b}$ & $-9,2 \pm 4,36 \mathrm{~b}$ & $1,31 \pm 0,61 \mathrm{a}$ & $2,09 \pm 0,54 \mathrm{a}$ \\
18 & $-3,3 \pm 4,18 \mathrm{~b}$ & $-10,5 \pm 5,21 \mathrm{~b}$ & $2,17 \pm 1,44 \mathrm{a}$ & $1,40 \pm 0,63 \mathrm{a}$ \\
24 & $-2,0 \pm 4,60 \mathrm{Aa}$ & $-10,0 \pm 6,07 \mathrm{Bb}$ & $1,25 \pm 0,70 \mathrm{a}$ & $1,40 \pm 0,49 \mathrm{a}$ \\
\hline
\end{tabular}

Letras maiúsculas distintas nas linhas significam diferença estatística entre os grupos. Letras minúsculas distintas nas colunas significam diferença entre o T0 e demais Tempos.

Tanto no G25\% quanto no G75\% foram observadas maiores concentrações de lactato-L apenas no T6 em relação ao T0 $(\mathrm{P}<0,05)$. Não existiu diferença dessa variável entre os grupos estudados em nenhum dos Tempos avaliados $(\mathrm{P}>0,05)$.

As respectivas quedas no $\mathrm{pH}$ sanguíneo, acima citadas, levaram a uma correspondente diminuição nos teores de bicarbonato e de $\mathrm{ABE}$, como o esperado e descrito na literatura (Owens et al., 1998; Maruta e Ortolani, 2002). A concentração de lactato-L sanguíneo se elevou significativamente nos dois grupos, não existindo diferença entre eles. Por problemas metodológicos, o isômero (lactato-D) não foi determinado.

Na Tabela 3, estão apresentados os resultados médios e desvios padrão da osmolaridade $(\mathrm{mOsm} / \mathrm{L})$, volume globular $(\mathrm{VG})$ e da glicose sanguínea no decorrer do experimento. Não foi verificada diferença nos valores de osmolaridade entre tempos dentro dos grupos $(\mathrm{P}>0,05)$. Porém houve diferença nos valores entre grupos no T3 e T12, tendo os ovinos do G75\% maior osmolaridade sérica que os do G25\% $(\mathrm{P}<0,01)$.
Menores valores do volume globular foram detectados dentro do G25\% no T3 e T6 em relação ao T0 $(\mathrm{P}<0,001)$. Todavia, não houve diferença entre os valores do volume globular na comparação entre grupos $(\mathrm{P}>0,05)$.

Maiores concentrações de glicose sanguínea foram detectadas dentro do G75\% no T3, T6 e T12 quando comparados ao T0 $(\mathrm{P}<0,05)$. Não existiu diferença dessa variável entre os dois grupos estudados $(\mathrm{P}>0,05)$.

A osmolaridade sanguínea foi maior no grupo G75\% do que no G25\% no T3 e T12. Mesmo com esse aumento, a osmolaridade em nenhum caso ultrapassou o limite de $310 \mathrm{mOsm} / \mathrm{L}$ considerado acima do valor de referência (Garza et al., 1989). Como os animais do G75\% não tiveram desidratação nem aumento do volume globular no decorrer do processo, os resultados podem indicar que, mesmo com a elevação da osmolaridade ruminal, a passagem de fluidos do sangue para o interior do rúmen parece ter sido diminuta ou nula, provavelmente devido à grande quantidade de fluidos $(92,72 \%$ da matéria original) presente no melão administrado. 
Avaliação hemogasométrica...

Tabela 3. Valores médios e desvios padrão da osmolaridade (mOsm/L), do VG (\%) e da glicose sanguínea nos ovinos alimentados com $25 \%$ e $75 \%$ de melão subitamente no decorrer do experimento

\begin{tabular}{ccccccc}
\hline Tempos & \multicolumn{2}{c}{ Osmolaridade $(\mathrm{mOsm} / \mathrm{L})$} & \multicolumn{2}{c}{$\mathrm{VG}(\%)$} & \multicolumn{2}{c}{ Glicose $(\mathrm{mMol} / \mathrm{L})$} \\
\hline & $\mathrm{G} 25 \%$ & $\mathrm{G} 75 \%$ & $\mathrm{G} 25 \%$ & $\mathrm{G} 75 \%$ & $\mathrm{G} 25 \%$ & $\mathrm{G} 75 \%$ \\
& $(\mathrm{M} \pm \mathrm{DP})$ & $(\mathrm{M} \pm \mathrm{DP})$ & $(\mathrm{M} \pm \mathrm{DP})$ & $(\mathrm{M} \pm \mathrm{DP})$ & $(\mathrm{M} \pm \mathrm{DP})$ & $(\mathrm{M} \pm \mathrm{DP})$ \\
\hline 0 & $270 \pm 10,71$ & $286 \pm 9,61$ & $26 \pm 3,7 \mathrm{a}$ & $29 \pm 6,4$ & $3,09 \pm 0,21$ & $2,94 \pm 0,69 \mathrm{~b}$ \\
3 & $271,7 \pm 4,59 \mathrm{~B}$ & $298,2 \pm 11,09 \mathrm{~A}$ & $23 \pm 2,0 \mathrm{~b}$ & $29 \pm 5,4$ & $4,34 \pm 0,61$ & $5,57 \pm 1,81 \mathrm{a}$ \\
6 & $271,3 \pm 10,13$ & $286,7 \pm 18,37$ & $23 \pm 2,3 \mathrm{~b}$ & $28 \pm 6,6$ & $4,44 \pm 0,61$ & $5,06 \pm 2,72 \mathrm{a}$ \\
12 & $265,8 \pm 4,40 \mathrm{~B}$ & $289,3 \pm 5,72 \mathrm{~A}$ & $24 \pm 3,1 \mathrm{a}$ & $30 \pm 6,9$ & $3,35 \pm 0,56$ & $4,59 \pm 1,23 \mathrm{a}$ \\
18 & $270,7 \pm 15,00$ & $282,5 \pm 6,50$ & $25 \pm 3,2 \mathrm{a}$ & $31 \pm 7,2$ & $3,84 \pm 0,19$ & $3,2 \pm 0,53 \mathrm{~b}$ \\
24 & $269,8 \pm 14,82$ & $280,5 \pm 9,77$ & $24 \pm 3,0 \mathrm{a}$ & $32 \pm 6,4$ & $3,21 \pm 0,45$ & $3,17 \pm 0,54 \mathrm{~b}$ \\
\hline
\end{tabular}

Letras maiúsculas distintas nas linhas significam diferença estatística entre os grupos. Letras minúsculas distintas nas colunas significam diferença entre os tempos de coleta e o momento basal.

O volume globular só apresentou alteração significativa dentro do G25\%, com diminuição dos valores após as primeiras seis horas de ingestão do melão. Tal resultado indica que ocorreu absorção de fluidos do rúmen nesse grupo. Acredita-se que o mesmo fenômeno tenha ocorrido nos ovinos do G75\%, a despeito dos resultados do volume globular. Tal especulação foi feita baseada na observação de intensa diurese que acometeu todos os ovinos desse grupo, a qual permaneceu a partir do T3 até o T12. É digno de nota que esses animais apresentaram hiperglicemia nesse período, característica nos casos de ALRA. É notório que a hiperglicemia estimula a diurese e que esse elevado status de glicose sanguíneo tenha sido provocado tanto pela absorção de ácido propiônico como pela própria sacarose do fruto (Kaneko et al., 1997; Radostits et al., 2007).

\section{CONCLUSÃO}

Os ovinos que receberam $25 \%$ de melão apresentaram poucas alterações sanguíneas, enquanto os ovinos do G75\% apresentaram alterações nos parâmetros sanguíneos indicativos de discreta acidose metabólica sistêmica e hiperglicemia.

\section{AGRADECIMENTOS}

Os autores são gratos à Fundação de Amparo à Pesquisa do Estado de São Paulo (Fapesp) pelo financiamento da pesquisa. A.H.H.M é grato ao CNPq pela bolsa de pós-doutorado concedida.

\section{REFERÊNCIAS}

BARRÊTO JÚNIOR, R.A.; MINERVINO, A.H.H.; RODRIGUES, F.A.M.L. et al. Avaliação do potencial da polpa cítrica em provocar acidose láctica ruminal aguda em bovinos. Braz. J. Vet. Res. Anim. Sci., v.45, p.419-427, 2008.

DUNLOP, R.H. Pathogenesis of ruminant lactic acidosis. Adv. Vet. Sci. Comp. Med., v.16, p.259302, 1972.

ENEMARK, J.M.D. The monitoring, prevention and treatment of sub-acute ruminal acidosis (SARA): a review. Vet. J., v. 176, p. 32-43, 2008.

GARZA, J.D.; OWENS, F.N.; BREAZILE, J.E. Effects of diet on ruminal liquid and on blood serum osmolality and hematocrit in feedlot heifers. Okla. Agric. Exp. Stn., MP-127, p. 68-76, 1989.

HOWARD, J.L. Ruminant metabolic acidosis. Bov. Pract., v.16, p.44-53, 1981.

JAIN, N.C. Schalm's veterinary hematology. Philadelphia: Lea \& Febiger,1986. p.1221.

KANEKO, J.J.; HARVEY, J.W.; BRUSS, M.L. Clinical biochemistry of domestic animals. 5.ed. New York: Academic Press, 1997. 932p.

KRAUSE, K.M.; GARRETT, M.; OETZEL, R. Understanding and preventing subacute ruminal acidosis in dairy herds: A review. Anim. Feed Sci. Technol., v.126, p.215-236, 2006. 
LIMA, C.A.C.; LIMA, G.F.C.; COSTA, R.G. et al. Efeito de níveis de melão em substituição ao milho moído sobre o desempenho, o consumo e a digestibilidade dos nutrientes em ovinos Morada Nova. Rev. Bras. Zootec., v.41, p.164-171, 2012.

LISBÔA, J.A.N.; MIRANDOLA, R.M.S.; BENESI, F.J. et al. Tempo de viabilidade de amostras de sangue venoso bovino destinadas ao exame hemogasométrico, quando mantidas sob conservação em água gelada. Cienc. Rural, v.31, p.271-276, 2001.

LOUSADA JÚNIOR, J.E.; NEIVA, J.N.M.; RODRIGUEZ, N.M.; PIEMNTEL, J. C. M.; LÔBO, R. N. B. Consumo e digestibilidade de subprodutos do processamento de frutas em ovinos. Rev. Bras. Zootec., v.34, p.659-669, 2005.

MARUTA, C.A.; ORTOLANI, E.L. Susceptibilidade de bovinos das raças Jersey e Gir à acidose láctica ruminal: I - variáveis ruminais e fecais. Cienc. Rural, v.32, p.55-59, 2002.

NAGARAJA, T.G.; LECHTENBERG, K.F. Acidosis in feedlot cattle. Vet. Clin. North Am. Food Anim. Pract., v.23, p.333-350, 2007.

NAGARAJA, T. G.; TITGEMEYER, E. C. Ruminal acidosis in beef cattle: the current microbiological and nutritional outlook. J. Dairy Sci., v.90, Suppl.1, p.E17-E38, 2007.

OFFICIAL methods of analysis of the Association of the Agricultural Chemists. 12. ed. Washington: AOAC, 1992.

ORTOLANI, E.L. Diagnóstico de doenças nutricionais e metabólicas por meio de exame de urina em ruminantes. In: SIMPÓSIO DE PATOLOGIA CLÍNICA VETERINÁRIA DA REGIÃO SUL DO BRASIL, 1., 2003, Porto Alegre. Anais... Porto Alegre: Universidade Federal do Rio Grande do Sul, 2003. p.91-102.
ORTOLANI, E.L.; BIRGEL, E.H.; ARAUJO, L.M.D. Behavior of rumen fluid ph of the cattle in vitro. Arq. Bras. Med. Vet. Zootec., v. 32, p.217-223, 1980

ORTOLANI, E.L.; MARUTA, C.A.; MINERVINO, A.H.H. Quadro clínico de zebuínos e taurinos submetidos à acidose láctica ruminal aguda. Braz. J. Vet. Res. Anim. Sci., v.47, p.253-261, 2010.

OWENS, F.N.; SECRIST, D.S.; HILL, W.J.; GILL D.R. Acidosis in cattle: a review. J. Anim. Sci., v.76, p.275-286, 1998.

RADOSTITS, O.M.; GAY, C.C.; HINCHCLIFF, K.W.; CONSTABLE, P.D. Veterinary medicine. 10.ed. London: Elsevier Saunders, 2007. p.2156.

REIS, L.F.; MINERVINO, A.H.H., ARAÚJO, C.A.S.C. et al. Comparison of rumen fluid $\mathrm{pH}$ by continuous telemetry system and bench $\mathrm{pH}$ meter in sheep with different ranges of ruminal Ph. Sci. World J., v.2014, art.195782, 2014.

SILVA, D.J.; QUEIRÒZ, A.C. Análise de alimentos: métodos químicos e biológicos. 3.ed. Viçosa: UFV, 2002. p.235.

SUCUPIRA, M.C.A.; ORTOLANI, E.L. Uso de sangue arterial e venoso no exame do equilíbrio ácido-básico de novilhos normais ou com acidose metabólica. Cienc. Rural, v.33, p.863868, 2003.

VIEIRA, A.C.S.; AFONSO, J.A.B.; MENDONÇA, C.L. et al. Estudo retrospectivo da acidose láctica em caprinos e ovinos atendidos na clínica de bovinos, Campus Garanhuns/UFRPE. Rev. Bras. Cienc. Agrar., v.1, p.97-101, 2006. 